\title{
Photochemical Cis/Trans Isomerization of a Stilbazolium Betaine. A Protolytic/Photochemical Reaction Cycle
}

\author{
U. Steiner, ${ }^{* 1 a}$ M. H. Abdel-Kader, ${ }^{\text {b }}$ P. Fischer, ${ }^{1 c}$ and H. E. A. Kramer ${ }^{1 a}$ \\ Contribution from the Institut für Physikalische Chemie and from the \\ Institut für Organische Chemie, Biochemie und Isotopenforschung, Universität Stuttgart, \\ Pfaffenwaldring 55, D-7000 Stuttgart 80, Federal Republic of Germany.
}

\begin{abstract}
Photochemical and thermal cis/trans isomerization is reported for a stilbazolium betaine (M), Obtained from synthesis in the trans configuration, $\mathrm{M}$ cannot be isomerized directly but only via the $\mathrm{O}$-protonated form $\mathrm{MH}_{\text {trans. }}^{+}$. Photoisomerization of $\mathrm{MH}_{\text {trans }}^{+}$yields the cis isomer $\mathrm{MH}_{\text {cis }}^{+}$(structure established by ${ }^{1} \mathrm{H}$ NMR) which can be deprotonated to the cis betaine. $\mathbf{M}_{\text {cis }}$ represents the first example of a cis isomer in this class of compounds. Though fairly stable in aqueous solution, $\mathbf{M}_{\text {cis }}$ can be fully reverted to the trans isomer either thermally or photochemically. The sequence $\mathrm{M}_{\text {trans }} \rightleftharpoons \mathrm{MH}_{\text {trans }}^{+} \rightleftarrows \mathrm{MH}_{\text {cis }}^{+} \rightleftarrows \mathrm{M}_{\text {cis }} \rightarrow$ $\mathrm{M}_{\text {trans }}$ constitutes a complete molecular reaction cycle which may serve as a chemical model for the storage of information and subsequent regeneration of the information carrier, for instance, in biological systems.
\end{abstract}

\section{Introduction}

Among the merocyanine dyes, merocyanines of the stilbazolium betaine type (I) have found continuing interest because of their extreme solvatochromic properties. The long-wavelength absorption maximum exhibits strong negative solvatochromy ${ }^{2,3}$ which has been rationalized qualitatively by assuming that for these compounds the large ground-state dipole moment is significantly reduced upon excitation. ${ }^{4 a, b}$ Bayliss and $\mathrm{McRae} \mathrm{e}^{5}$ have shown that the underlying change in electronic structure is mainly due, though, to the hydrogen bonding capability of the solvent rather than its bulk polarity. The same concept has successfully been utilized by Benson and Murrell ${ }^{6}$ to account for the solvent influence in a $\pi$-electron SCF calculation of excitation energy and oscillator strength of the stilbazolium betaine $\mathrm{M}$.

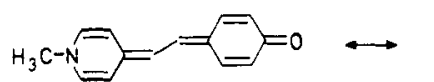

Ia

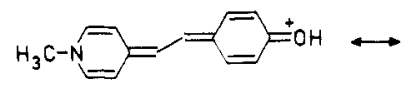

II

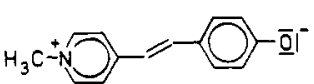

Ib

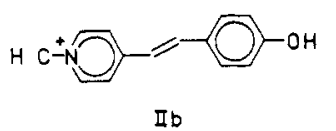

In valence bond terminology, these experimental results and theoretical arguments can be interpreted as predominant contribution of the polar resonance structure, $\mathrm{Ib}$, to the ground state of stilbazolium betaines in polar solvents. Ib represents an essentially stilbene-analogous structure, with two benzenoid rings and an ethylenic $\mathrm{C}=\mathrm{C}$ double bond, offering the possibility of cis/trans isomerism known for many stilbene derivatives. Thus, one should expect stilbazolium betaines to likewise exist in a cis as well as in the trans configuration, and the cis isomer, though thermodynamically less favorable, to be sufficiently stable for at least spectroscopic identification.

So far, however, no cis stilbazolium betaines have been reported in the literature, except for a paper of Schulte-Frohlinde and Guesten ${ }^{7}$ who in 1971 proposed a cis stilbazolium betaine as an intermediate in the thermal cis $\rightarrow$ trans isomerization of a hydroxystyryl-quinolinium cation, i.e., the O-protonated form of the betaine. Since the rate of isomerization was found to be inversely proportional to the $\mathrm{H}^{+}$concentration, the authors supposed the reaction to in fact proceed via the corresponding cis stilbazolium betaine which they assumed to be present in protolytic equilibrium, but to be too short lived even for spectroscopic detection. ${ }^{7}$

We now want to report the successful photochemical and thermal trans $\rightleftarrows$ cis isomerization of 1-methyl-4-(4-hydroxystyryl)pyridinium betaine ( $M$ ) and its protonated form, $\mathrm{MH}^{+}$, both of which have hitherto been known only in the trans configuration. The species $\mathbf{M}_{\text {cis }}$ represents the first example of a cis stilbazolium betaine sufficiently long lived to allow spectral characterization as well as a detailed investigation of its photochemical properties. Kuder and Wychik, ${ }^{8}$ who have recently determined the $\mathrm{p} K$ values of $\mathrm{MH}^{+}$in ground and excited singlet state, do not report any indication of isomerization. We have found, though, that this type of merocyanine is ideally suited for a detailed study of cis/trans isomerism in a conjugate acid/base system.

\section{Experimental Section}

Materials. $4^{\prime}$-Hydroxy-1-methylstilbazolium betaine was synthesized according to literature procedures ${ }^{3}$ and recrystallized several times from water, and its purity was checked by TLC on aluminum oxide (neutral) and silica gel $60 \mathrm{~F}_{254}$ (Merck). Deionized water was distilled twice in a quartz column; methanol (p.a. Merck) was used without purification. $\mathrm{HCl}$ and $\mathrm{NaOH}$ (1 N Titrisol, Merck), $\mathrm{Na}_{2} \mathrm{~B}_{4} \mathrm{O}_{7} \cdot 10 \mathrm{H}_{2} \mathrm{O}$ ) (p.a. Merck), and buffer solutions of $\mathrm{pH} 6,7,8$, 9 , and 10 (Puffer-Titrisol Merck) were used as buffer materials; the buffer of pH 8.5 was prepared as described by Bates and Bower. ${ }^{9}$ Quinine bisulfate (Fluka) served as a fluorescence standard.

Instrumentation. $\mathrm{UV}$ and visible absorption spectra were recorded on a Zeiss DMR 10 spectrophotometer with a cuvette holder equipped for variable temperature thermostatization.

The fluorescence measurements were made on a Hitachi/PerkinElmer spectrophotometer MPF-32. Fluorescence intensities were measured at right angle to the exciting light. Narrow entrance slits were used in order to minimize the intensity of the exciting light and thus to keep photoisomerization at a low rate. Owing to the high quantum yields of some of the species investigated, photoisomerization could not always be excluded completely. In these cases, the fluorescence intensity was recorded as a function of time, at fixed wavelengths for both excitation and detection, and extrapolated to $t=0$. Fluorescence quantum yields were based on quinine bisulfate in $1 \mathrm{~N} \mathrm{H}_{2} \mathrm{SO}_{4}$ as spectral and quantum standard $\left(\Phi_{\mathrm{F}}=0.55 \mathrm{at} \lambda=366 \mathrm{~nm}^{10}\right)$. In order to avoid photochemically induced concentration changes during the recording of the spectra, solutions of the merocyanine or its conjugate acid were used in these measurements with cis/trans isomer ratios corresponding to the composition of the photostationary state for the respective wavelengths.

Fluorescence lifetimes were measured with a $100-\mathrm{MHz}$ phase fluorometer described by Hauser and Heidt. ${ }^{11}$ The exciting light 
Table I. ${ }^{1} \mathrm{H}$ NMR Data (in $\left.\mathrm{CD}_{3} \mathrm{OD}, 30^{\circ} \mathrm{C}\right)^{a}$ for 1-Methyl-4-(4-hydroxystyryl)pyridinium Betaine, $\mathrm{M}_{\mathrm{trans}}$, and the Protonated Isomeric Forms, $\mathrm{MH}_{\text {trans }}^{+}$and $\mathrm{MH}_{\mathrm{cis}}^{+}$

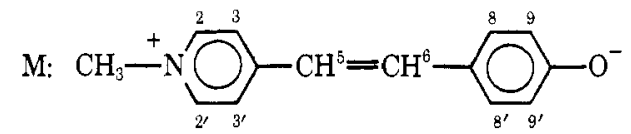

\begin{tabular}{|c|c|c|c|c|c|c|c|c|c|}
\hline & \multicolumn{6}{|c|}{$\delta(\mathrm{ppm})^{b}$} & \multicolumn{3}{|c|}{$J, \mathrm{~Hz}$} \\
\hline & $\mathrm{H}^{2,2^{\prime}}$ & $\mathrm{H}^{3,3^{\prime}}$ & $\mathrm{H}^{5}$ & $\mathrm{H}^{6}$ & $\mathrm{H}^{8,8^{\prime}}$ & $\mathrm{H}^{9,9^{\prime}}$ & $\mathrm{H}^{5} \mathrm{H}^{6}$ & $J_{\text {ortho }}^{2,3}$ & $\mathrm{H}^{8} \mathrm{H}^{9} / \mathrm{H}^{8} \mathrm{H}^{9}$ \\
\hline 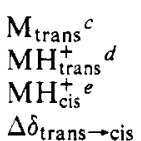 & $\begin{array}{r}8.34 \\
8.62 \\
8.60 \\
-0.02\end{array}$ & $\begin{array}{r}7.81 \\
8.06 \\
7.82 \\
-0.24\end{array}$ & $\begin{array}{r}6.868 \\
7.202 \\
6.585 \\
-0.62\end{array}$ & $\begin{array}{r}7.758 \\
7.853 \\
7.165 \\
-0.69\end{array}$ & $\begin{array}{r}7.433 \\
7.613 \\
7.177 \\
-0.435\end{array}$ & $\begin{array}{c}6.594 \\
6.861 \\
6.748 \\
-0.11\end{array}$ & $\begin{array}{l}15.8 \\
16.2 \\
12.1\end{array}$ & $\begin{array}{l}(7.1)^{f} \\
(7.0)^{f} \\
(6.8)^{f}\end{array}$ & $\begin{array}{l}8.63 / 0.09 \\
8.44 / 0.21 \\
8.25 / 0.20\end{array}$ \\
\hline
\end{tabular}

${ }^{a}$ For technical details, see Experimental Section. ${ }^{b}$ Relative to $\mathrm{Me}_{4} \mathrm{Si}$ as internal standard. ${ }^{c}{ }^{c} 5 \times 10^{-3} \mathrm{~mol} / \mathrm{L} .{ }^{d}$ Concentration of $\mathrm{MH}_{\text {trans }}^{+}$ $5 \times 10^{-2} \mathrm{~mol} / \mathrm{L}$, of DCl $1 \times 10^{-1} \mathrm{~mol} / \mathrm{L}$. ${ }^{e}$ Part of the photostationary state cis/trans isomer mixture (60:40), total concentration of $\mathrm{MH}_{\text {trans }}^{+}$ $+\mathrm{MH}_{\mathrm{cis}}^{+} 2 \times 10^{-2} \mathrm{~mol} / \mathrm{L}$, of $\mathrm{DCl} 4 \times 10^{-2} \mathrm{~mol} / \mathrm{L}$. $f$ Because of the lack of fine structure, the $\mathrm{H}^{2,2^{\prime}} / \mathrm{H}^{3,3^{\prime}}$ resonances were analyzed as simple first-order $\mathrm{AB}$ patterns. The $\delta$ and $J$ values for $\mathrm{H}^{5,6}$ and $\mathrm{H}^{8,8^{\prime}, 9,9^{\prime}}$ represent the best values from iterative calculations (NIC-17-30712).

source was a Spectra Physics Model 164 argon ion laser. For fluorescence excitation, the 454.4-nm line was used in the case of the merocyanine, and the $363.8 / 356.4 \mathrm{~nm}$ lines in the case of the protonated species. Lifetimes $\tau$ were calculated, assuming exponential decay, from the equation $\tan \phi=\omega \tau$.

Photoisomerization. The samples were irradiated in cylindrical cuvettes of $2.5-\mathrm{mL}$ volume and $10-\mathrm{mm}$ optical path length, placed in a thermostat. These cuvettes could also be inserted into the sample holder of the absorption spectrophotometer for recording of the absorption spectra at different stages of the photoreaction. As photochemical light sources, a mercury high-pressure lamp (HBO $200 \mathrm{~W} / 2$, Osram), combined with interference filters (maximum transmission at 365 and $435 \mathrm{~nm}$, spectral width at half transmission 8 and $17 \mathrm{~nm}$, respectively) to select the $\mathrm{Hg}$ lines at 366 and $436 \mathrm{~nm}$, and a lowpressure mercury lamp (NK 6/20, Hanau), combined with a reflection filter (UV-R-250, Schott) to select the $254-\mathrm{nm} \mathrm{Hg}$ line, were used.

To determine photochemical quantum yields, the time dependence of transmission was followed directly in the irradiating apparatus, using the incident light simultaneously as probe light. The light intensity at the far side of the cuvette was detected by a photomultiplier and recorded on a Philips PM 8251 recorder. For absolute measurements of the incident light intensity, ferrioxalate actinometry was used as described by Hatchard and Parker. ${ }^{12}$ For experiments with exclusion of oxygen, the samples were deaerated by passing a $\mathrm{N}_{2}$ stream (oxygen content $<5 \mathrm{ppm}$ ) through the cuvettes for $0.5 \mathrm{~h}$.

NMR Measurements. The ' $\mathrm{H}$ NMR spectra were obtained in pulse Fourier transform mode on a Bruker HX 90E spectrometer, equipped with a 15-in. magnet, BSV 3 PM pulse unit, and a Nicolet BNC 12 computer with $16 \mathrm{~K}$ data memory. Pulse width was set at $5 \mu$ s (corresponding to about $35^{\circ}$ flip angle). The spectral width was 892.8571 $\mathrm{Hz}$; thus, with a dwell time of $560 \mu \mathrm{s} /$ address, the total acquisition time for one $16 \mathrm{~K}$ FID ( repetition rate) amounted to $9.1_{8} \mathrm{~s}$. For optimum resolution, samples were run in $5 \cdot \mathrm{mm}$ tubes only, with the $C D_{3} \mathrm{OD}$ resonance as ${ }^{2} \mathrm{D}$ lock signal. $\mathrm{CD}_{3} \mathrm{OD}(99 \% \mathrm{D}$, Sharpe \& Dohme) was used as solvent, $\mathrm{DCl}$ ( $37 \%$ in $\mathrm{D}_{2} \mathrm{O}$, Merck Uvasol) for acidification, and $\mathrm{NaOD}$ ( $40 \%$ in $\mathrm{D}_{2} \mathrm{O}$, Merck Uvasol) for subsequent deprotonation. The sample concentrations of the various merocyanine forms were in the range of $5 \times 10^{-3}$ to $5 \times 10^{-2} ; \mathrm{DCl}$ concentration was $4 \times 10^{-2}$. On the average, 4000-7000 scans were taken for each single spectrum.

The numerical analysis of the NMR spectra was started with a first-order evaluation of each of the three subsets ( $\mathrm{AA}^{\prime} \mathrm{XX}^{\prime}$ pyridinium, $\mathrm{AA}^{\prime} \mathrm{XX}^{\prime}$ phenoxy, and $\left.\mathrm{AB}_{\text {olef }}\right)$, followed where feasible by an iterative parameter refinement with the Nicolet program ITRCL1/2 (NIC 17.30712); the final $\delta$ and $J$ values are listed in Table I. For the digital subtraction, the $\mathrm{MH}^{+}$spectrum was scaled to the correct height by adjusting the $\mathrm{H}^{3,3^{\prime}}$-pyridinium and the $\mathrm{H}^{8,8^{\prime}}$-phenoxy "doublet" in both intensity and line width to the respective signals of the composite trace; finally, the of fset was corrected for identical centroid position of nonoverlapping resonances (Figure $3 \mathrm{~A} / \mathrm{B}$ ). Owing to slight changes in chemical shift between the pure trans solution and the cis/trans mixture, however, an absolutely exact fit could not be obtained, and the $\mathrm{MH}_{\text {cis }}^{+}$subtraction spectrum (Figure $3 \mathrm{C}$ ) still retains some $\mathrm{MH}_{\text {trans }}^{+}$ signal intensity (with both positive and negative sign).

Methods of Calculation. Cis Isomer Absorption Spectra. To analyze the cis/trans isomer composition at the individual photostationary states, reached by irradiating solutions of pure trans compound at two different wavelengths, the method described by Fischer ${ }^{13}$ was used. After determination of the cis/trans ratio by this method, the spectrum of the cis isomer can be calculated from the spectra of the isomer mixture and the pure trans merocyanine. Fischer's method also yields the ratio of the quantum yields cis $\rightarrow$ trans $\left(\Phi_{c \rightarrow t}\right)$ and trans $\rightarrow$ cis $\left(\Phi_{t \rightarrow c}\right), \Phi_{c \rightarrow t} / \Phi_{t \rightarrow c}$ being assumed to be independent of the excitation wavelength.

As a second independent method we applied the procedure developed by Blanc and Ross ${ }^{14}$ for a mixture of two isomers only one of which shows fluorescence. This method allows the determination of the absolute absorption spectrum of the nonfluorescing isomer even if the absorption spectrum of the fluorescing isomer is unknown. The formulas as given by Blanc and Ross are not quite exact, however, in that fluorescence intensities of solutions with different optical densities are compared. Since the geometric factor is different for the two samples in the case of different optical densities, we compared only solutions with different total concentrations of the isomers but with equal optical densities $(D)$ at the excitation wavelength. ${ }^{15}$ For this method, the molar excitation coefficient of the cis isomer at the excitation wavelength, $\epsilon_{\mathfrak{c}}$, is given by eq 1 (which is the analogue of eq 5 in the original work ${ }^{14}$ ).

$$
\epsilon_{\mathrm{c}}=\frac{I_{\mathrm{F}_{1}}-I_{\mathrm{F}_{2}}}{c_{2} I_{\mathrm{F}_{1}}-c_{1} I_{\mathrm{F}_{2}}} \frac{D}{d}
$$

In eq $1, I_{\mathrm{F}_{1}}$ and $I_{\mathrm{F}_{2}}$ are the fluorescence intensities of the solutions with total concentrations $c_{1}$ and $c_{2}$, and $d$ is the optical path length of the cuvettes. As eq 5 of ref 14, expression 1 for $\epsilon_{c}$ does not involve explicitly the actual cis/trans ratio in the respective solutions. To obtain optimal accuracy, however, the cis/trans ratios of the two solutions should differ as much as possible.

Quantum Yields $\Phi_{t \rightarrow c}$ and $\Phi_{c \rightarrow t}$. On irradiation with monochromatic light of intensity $I_{0}$, the optical density $D$ of a solution containing cis and trans isomer in a total concentration $c$ changes according to

$$
\mathrm{d} D / \mathrm{d} t=-\left(1-10^{-D}\right) I_{0} \frac{1}{D}\left(\epsilon_{\mathrm{t}}-\epsilon_{\mathrm{c}}\right)\left(D_{\mathrm{t}} \Phi_{\mathrm{t} \rightarrow \mathrm{c}}-D_{\mathrm{c}} \Phi_{\mathrm{c} \rightarrow \mathrm{t}}\right)
$$

$D_{\mathrm{c}}$ and $D_{\mathrm{t}}$ are the fractions of optical density due to the cis and trans isomer, respectively, and can be calculated from $D$ by the following relationships

$$
\begin{gathered}
D_{\mathrm{t}}=\frac{D /(c d)-\epsilon_{\mathrm{c}}}{\epsilon_{\mathrm{t}}-\epsilon_{\mathrm{c}}} c d \epsilon_{\mathrm{t}} \\
D_{\mathrm{c}}=-\frac{D /(c d)-\epsilon_{\mathrm{t}}}{\epsilon_{\mathrm{t}}-\epsilon_{\mathrm{c}}} c d \epsilon_{\mathrm{c}}
\end{gathered}
$$

Thus, by using the values for $\epsilon_{t}, \epsilon_{c}$, and $\Phi_{c \rightarrow t} / \Phi_{t \rightarrow c}$ as determined by the methods described above, the individual quantum yields may be calculated from the measured value of $\mathrm{d} D / \mathrm{d} t$.

\section{Results}

At the outset of our investigations, we found the absorption spectra of the merocyanine $M$ in aqueous solutions of different $\mathrm{pH}$ to be badly reproducible. Especially, there were no sharp isosbestic points as would be expected for a simple protolytic 


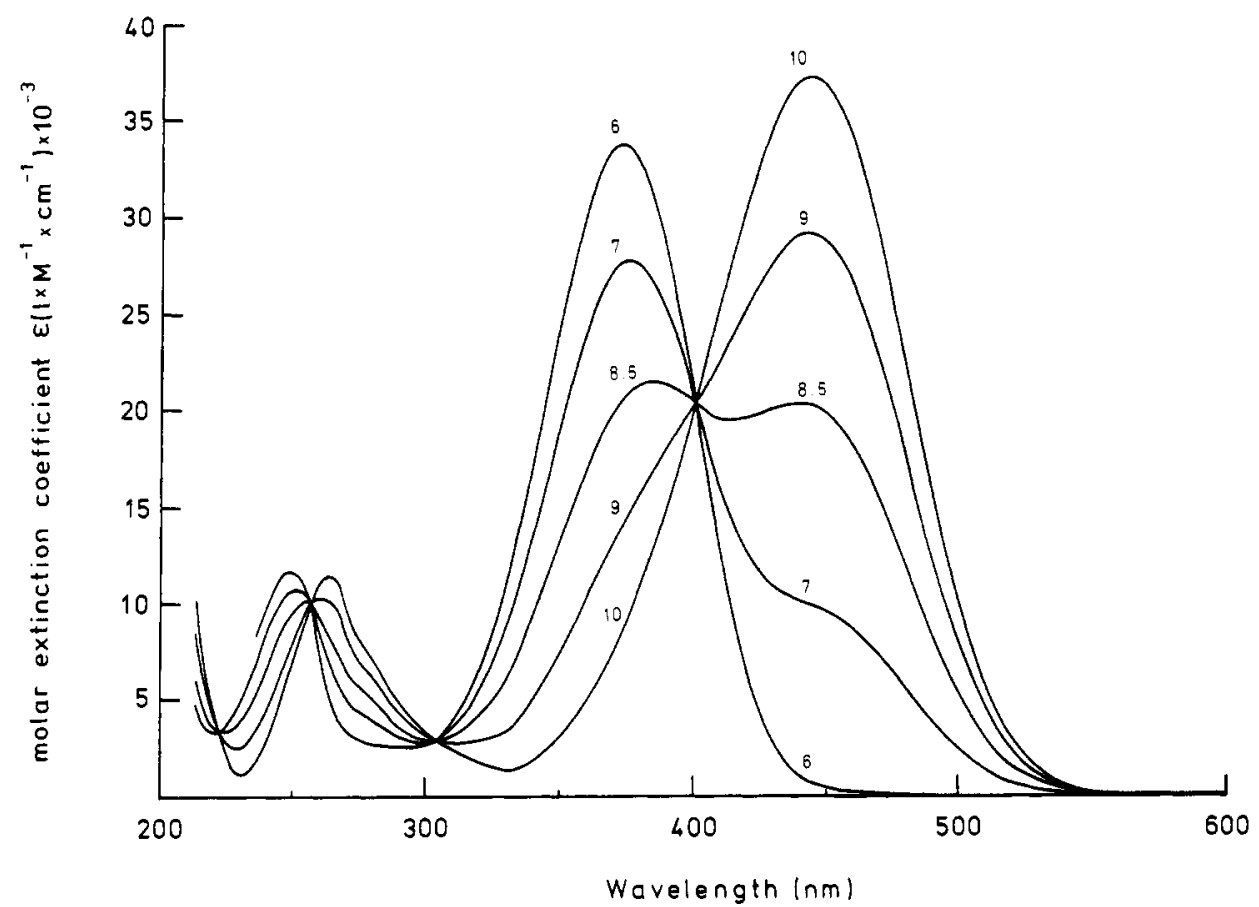

Figure 1. Absorption spectra of aqueous solutions of $\mathrm{M}$ at different $\mathrm{pH}\left(c 2 \times 10^{-5} \mathrm{~mol} / \mathrm{L}\right.$, solutions handled only in the dark).

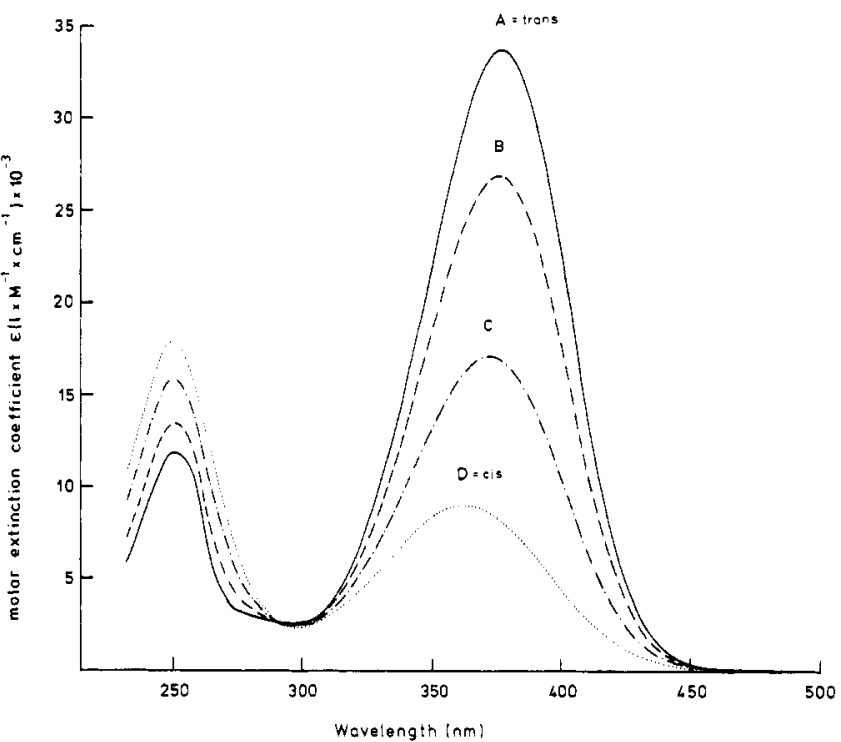

Figure 2. Spectral change for aqueous solutions of $\mathrm{MH}^{+}\left(c 2 \times 10^{-5}\right.$ $\mathrm{mol} / \mathrm{L}, \mathrm{pH}$ 6) upon irradiation: (A) spectrum before irradiaton (pure trans); (B) photostationary state spectrum for irradiation at $254 \mathrm{~nm}$; (C) photostationary state spectrum for irradiation at $366 \mathrm{~nm}$; (D) calculated spectrum of pure cis isomer.

equilibrium of only two forms, $\mathrm{M}$ and $\mathrm{MH}^{+}$. When the solutions were handled only in the dark, however, the spectra became exactly reproducible and showed sharp isosbestic points (Figure 1). From these spectra, the $\mathrm{p} K$ at $25^{\circ} \mathrm{C}$ was evaluated as 8.54 , in perfect agreement with the literature value. ${ }^{8}$ Since at a $\mathrm{pH} \geqslant 10$ where protonation of $\mathrm{M}$ is negligible solutions of $M$ are photochemically stable, these findings are suggestive of a photoreaction of the protonated form, $\mathrm{MH}^{+}$. In fact, solutions of the merocyanine at $\mathrm{pH} \leq 6$ (where only $\mathrm{MH}^{+}$is present) display reversible photochromism as illustrated by the several spectral traces in Figure 2.

The Photochemistry of $\mathrm{MH}^{+}$. If a solution of $\mathrm{MH}^{+}$, prepared in the dark by dissolving $\mathrm{M}$ in a buffer solution of $\mathrm{pH} 6$ (Figure 2, spectrum A), is irradiated at $366 \mathrm{~nm}$, the absorbance of the long-wavelength band ( $\lambda_{\max }$ initially at $372 \mathrm{~nm}$ in trace
A) decreases, with a concomitant increase in intensity of the second band ( $\lambda_{\max } 248 \mathrm{~nm}$ ), until a stationary state is reached (Figure 2, spectrum C). By irradiating this solution (C) in the shorter wavelength band $(254 \mathrm{~nm})$, the spectral change $(\mathrm{A} \rightarrow$ $C)$ is partially reversed until a new photostationary state is reached (spectrum B). The same spectrum (B) can also be obtained when the initial solution $(A)$ is subjected directly to irradiation at $254 \mathrm{~nm}$. Both the sharp isosbestic points (Figure 1) and, more generally, ${ }^{16}$ a linear correlation between the absorbances at two different wavelengths indicate that the observed spectral change is in fact due to a single, reversible photoreaction.

A probable explanation for the photochemical process would be a (reversible) trans $\rightleftarrows$ cis isomerization about the central $\mathrm{C}=\mathrm{C}$ bond of $\mathrm{MH}^{+}$. For structural proof of the newly formed compound, ' $\mathrm{H}$ NMR spectra in $\mathrm{CD}_{3} \mathrm{OD} / \mathrm{DCl}$ were measured of both the initial solution prepared in the dark and of the same solution after irradiation. By using pulse Fourier technique, these spectra could be obtained directly from low-concentration samples which could also be subjected to UV analysis. Thus, an unequivocal intercorrelation between UV and NMR results was established.

${ }^{1} \mathrm{H}$ NMR Analysis. Figure $3 \mathrm{~A}$ shows the ${ }^{1} \mathrm{H}$ NMR spectrum of the protonated merocyanine, $\mathrm{MH}^{+}$, in $\mathrm{CD}_{3} \mathrm{OD} / \mathrm{DCl}$ solution. There are three well-separated, independent partial spectra: one $\mathrm{AA}^{\prime} \mathrm{XX}^{\prime}$ pattern each for the phenoxy and the pyridinium moiety ( for the latter, none of the lines belonging to the two "ab quartets" appears resolved), and a pair of doublets for the AB system of the two olefinic protons. The $\mathrm{H}^{5} \mathrm{H}^{6}$ coupling constant, $J_{\mathrm{AB}}=16.2 \mathrm{~Hz}$, is compatible only with a trans configuration of the two aryl substituents about the central $\mathrm{C}=\mathrm{C}$ double bond ${ }^{17,18}$ (Figure $3 \mathrm{~A}$, Table I).

After irradiation to a photostationary state, the proton spectrum of the same solution displays, in addition to the original set of resonances, a large number of new lines (Figure 3B). Upon digital subtraction of the spectrum of $\mathrm{MH}_{\text {trans }}^{+}$before irradiation from the composite trace (for details, see Experimental Section), it becomes evident that the resonances of the newly formed compound can again be classified into three separate partial spectra. Two of these are $\mathrm{AA}^{\prime} \mathrm{XX}^{\prime}$ systems which-despite considerable changes in chemical shift- 
exhibit exactly the same "fine structure" (splitting, relative intensity, resolution) observed for the phenoxy and pyridinium ring protons of $\mathrm{MH}_{\text {trans. }}^{+}$. For the new pair of $\mathrm{AB}$ doublets, however, $J_{\mathrm{AB}}$ is only $12.1 \mathrm{~Hz}$-a value which is in perfect accord with a cis arrangement of the two arene moieties. ${ }^{17,18}$

The NMR spectrum thus supports our original assumption that the protonated trans merocyanine is partially photoisomerized to the corresponding cis compound. The NMR analysis, especially the spectral subtraction, also shows that, as already demonstrated by the well-defined isosbestic points in the absorption spectrum, one and-within the limits of ${ }^{1} \mathrm{H}$ NMR detection-only one product is formed in the photochemical process.

It now remains to be examined whether the changes in chemical shifts between $\mathrm{MH}_{\text {trans }}^{+}$and the new isomer likewise are compatible with a cis merocyanine structure. In this configuration, as in cis-stilbene, the two arene rings must obviously be twisted from the coplanar orientation relative to the $\mathrm{C}^{5}=\mathrm{C}^{6}$ bond. Thus, one might expect considerable attenuation for the cis compound of both the electron withdrawal by the $1-\mathrm{N}^{+}-$ $\mathrm{CH}_{3}$ function (which exerts its influence mainly at positions 6 and $8,8^{\prime}$ in the other ring) and the $+\mathrm{M}$ effect of the $\mathrm{OH}$ group (which should be felt mainly by $\mathrm{H}^{5}$ and $\mathrm{H}^{3,3^{\prime}}$ ). There is no significant effect of the associated decrease in charge exchange on the actual chemical shift, for both $\mathrm{H}^{5}$ and $\mathrm{H}^{6}$ move upfield to nearly the same extent (Figure $3 \mathrm{~A} \rightarrow 3 \mathrm{C}$ ). On the other hand, these protons lie within the deshielding region of the aromatic ring current in the coplanar configuration of the trans compound; upon rotation of the arene rings about the $\mathrm{C}^{4}-\mathrm{C}^{5}$ and $\mathrm{C}^{6}-\mathrm{C}^{7}$ bonds, respectively, $\mathrm{H}^{5}$ and $\mathrm{H}^{6}$ may eventually even come into the screening cone of the anisotropic ring current, and thus appear considerably better shielded for the cis than for the trans isomer. At the same time, the aryl protons in ortho position to the olefinic linkage $\left(\mathrm{H}^{3,3^{3}}\right.$ and $\mathrm{H}^{8,8^{\prime}}$, respectively) each are situated well within the shielding cone of the other arene ring for the cis configuration, and thus should experience a significant high-field shift; this is in fact observed (Table I).

The ${ }^{1} \mathrm{H}$ NMR findings as outlined above represent conclusive proof that the photoisomer of $\mathrm{MH}_{\text {trans }}^{+}$is indeed the cis merocyanine, $\mathrm{MH}_{\text {cis. }}^{+}$. The photostationary state spectrum (Figure 3B) also allows calculation of the cis/trans isomer ratio. In the composite trace, the individual resonances can be assigned to the various ${ }^{1} \mathrm{H}$ sites in both cis and trans isomer, as indicated in Figure 3, and the four well-separated resonance areas may be integrated separately. Thence, cis/trans is calculated as 0.60 ; if one takes into account the change of solvent $\left(\mathrm{CH}_{3} \mathrm{OH}\right.$ vs. $\left.\mathrm{H}_{2} \mathrm{O}\right)$, this is in good agreement with the value for the photostationary state as determined from the absorption spectra ( 0.67 for irradiation at $366 \mathrm{~nm}$ in aqueous solution, see below).

Quantum Yields. The nature of the photoproduct being established, it was of interest to determine the quantum yields of both the trans $\rightarrow$ cis and the cis $\rightarrow$ trans photoisomerization (which should provide information on the mechanism of the photoreaction). For this, the spectrum of the pure cis isomer must be known. From the spectra of the photostationary states obtained by irradiation at 254 and $366 \mathrm{~nm}$ (Figure 2, spectra $\mathrm{B}$ and $\mathrm{C}$ ) and from the pure trans spectrum $(\mathrm{A})$, the fraction of cis compound in the corresponding solutions can be calculated by Fischer's method ${ }^{13}$ (see Methods of Calculations) as 0.27 and 0.67 , respectively. Thence, it is also possible to calculate the spectrum of pure $\mathrm{MH}_{\text {cis }}^{+}$(Figure 2, spectrum D; $\epsilon_{\text {cis }}^{366 \mathrm{~nm}}$ $9.2 \times 10^{3} \mathrm{~L} \mathrm{~mol}^{-1} \mathrm{~cm}^{-1}$ ). It should be noted that the spectral change in going from $\mathrm{MH}_{\text {trans }}^{+}$to $\mathrm{MH}_{\mathrm{cis}}^{+}$is quite similar to that between trans- and cis-stilbene.

The photostationary state solution (C) was also subjected to the fluorescence analysis method of Blanc and Ross ${ }^{14}$ (see Methods of Calculation) by comparing it with a pure $\mathrm{MH}_{\text {trans }}^{+}$
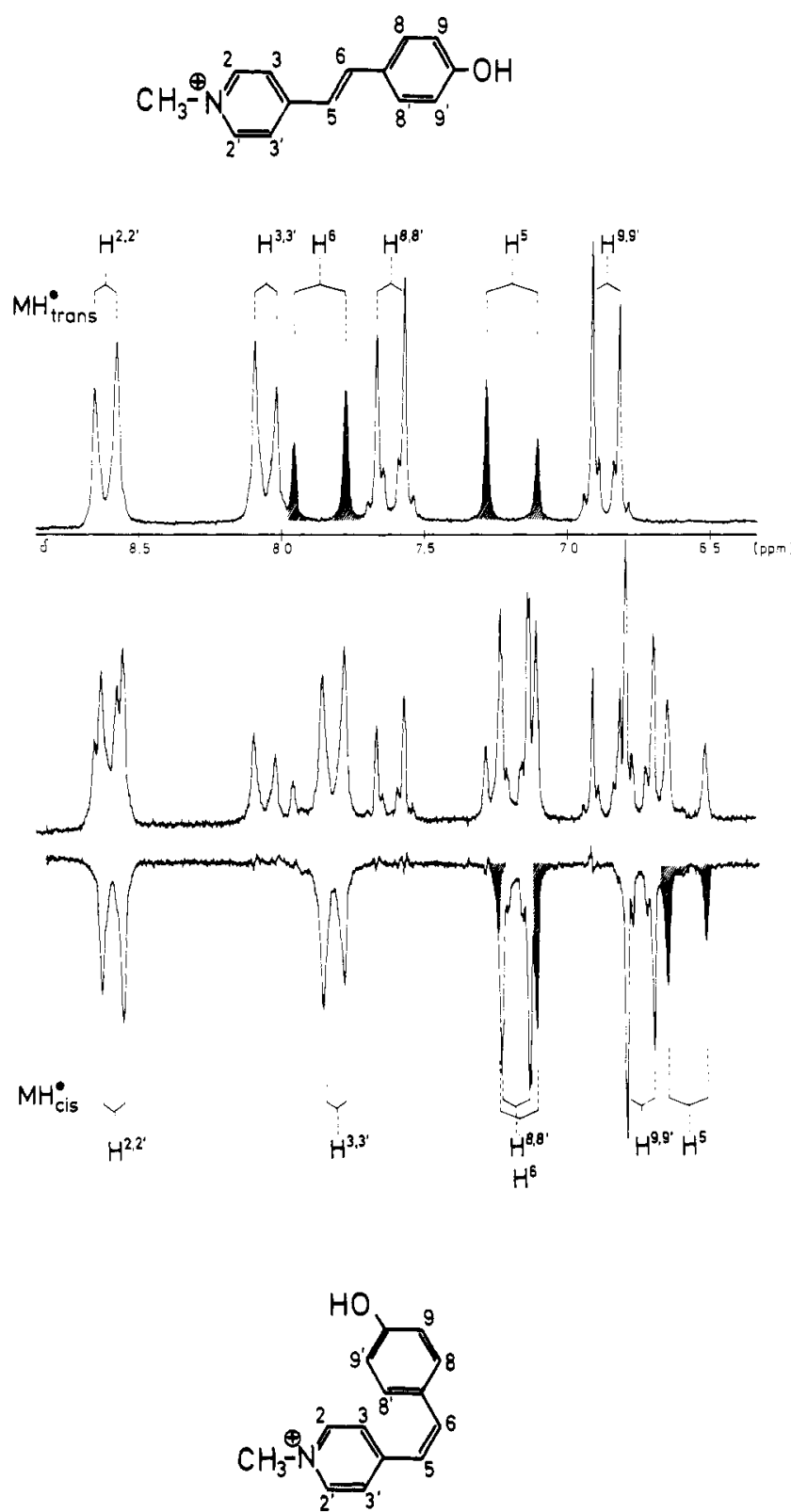

Figure 3. Aryl proton spectra of $\mathrm{MH}^{+}$(assignment of partial spectra follows the numbering in the accompanying structural formulas; the two $A B$ doublets of the olefinic protons $\mathrm{H}^{5,6}$ are shaded for better clarification): (A) spectrum of unchanged $\mathrm{MH}_{\text {trans }}^{+}$(handled only in the dark, $c 5 \times 10^{-2}$ $\mathrm{mol} / \mathrm{L}$ ); (B) spectrum for the photostationary state composition after irradiation at $366 \mathrm{~nm}\left(\mathrm{MH}_{\mathrm{cis}}^{+}: \mathrm{MH}_{\text {trans }}^{+} 60: 40\right.$, total concentration $2 \times 10^{-2}$ $\mathrm{mol} / \mathrm{L}$ ); (C) spectrum of pure cis isomer obtained by digital subtraction of the $\mathrm{MH}_{\text {trans }}^{+}$spectrum (see text) from the composite trace (B).

solution (A). The calculation yields $\epsilon_{\mathrm{cis}}^{366 \mathrm{~nm}} 9.25 \times 10^{3} \mathrm{~L} \mathrm{~mol}^{-1}$ $\mathrm{cm}^{-1}$, in excellent agreement with the value obtained by Fischer's method. The underlying assumptions of both methods thus seem to be justified, (1) that the ratio of the quantum yields $\Phi_{\mathrm{c} \rightarrow \mathrm{t}} / \Phi_{\mathrm{t} \rightarrow \mathrm{c}}$ is identical at 254 and $366 \mathrm{~nm}$, and (2) that the fluorescence quantum yield of the cis isomer is negligible.

With the $\epsilon_{t}, \epsilon_{c}$, and $\Phi_{c \rightarrow t} / \Phi_{t \rightarrow c}$ values determined above, the individual quantum yields $\Phi_{c \rightarrow t}$ and $\Phi_{t \rightarrow c}$ can be calculated from the time dependence of the optical density on irradiation. The results are given in Table II together with the fluorescence quantum yield and the fluorescence lifetime of the trans isomer. The quantum yields are independent of the presence of oxygen and, within the range of $\mathrm{MH}^{+}$concentrations used $\left(\max 4 \times 10^{-5} \mathrm{M}\right)$, also of the concentration of $\mathrm{MH}^{+}$. 


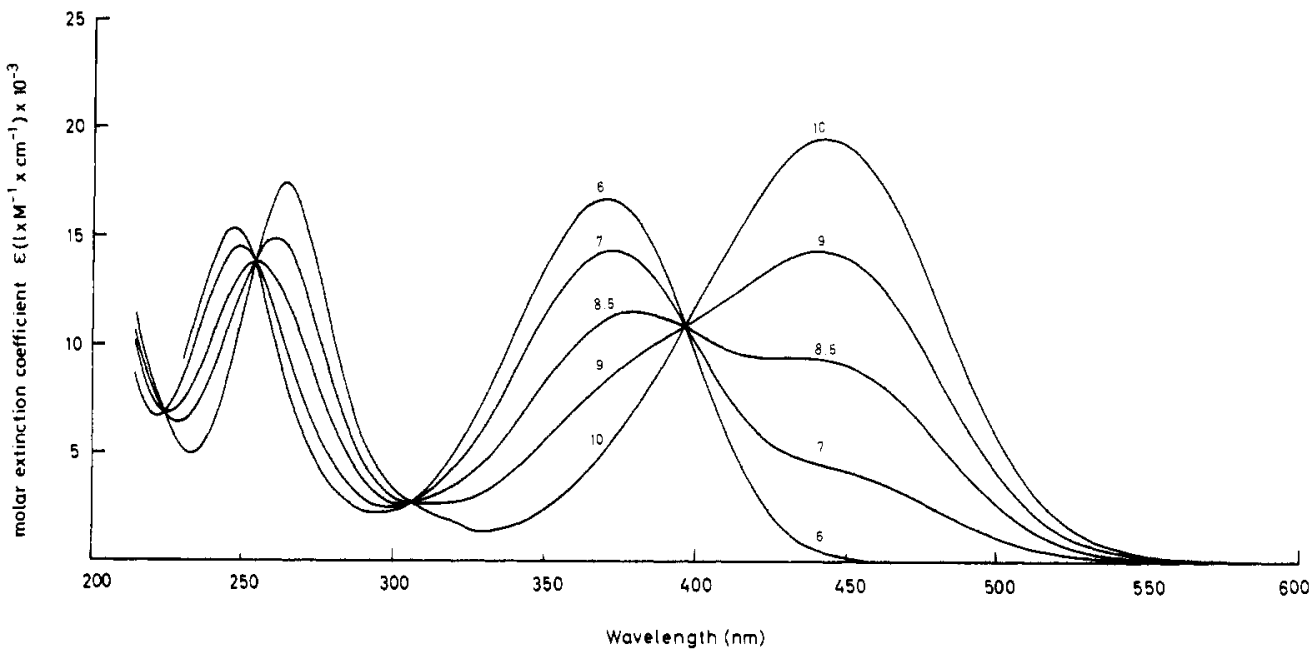

Figure 4. Absorption spectra of a 67:33 isomer mixture of $\mathrm{MH}_{\text {cis }}^{+}$and $\mathrm{MH}_{\text {trans }}^{+}$(aqueous solution, total concentration $2 \times 10^{-5} \mathrm{~mol} / \mathrm{L}$ ) at different $\mathrm{pHs}$.

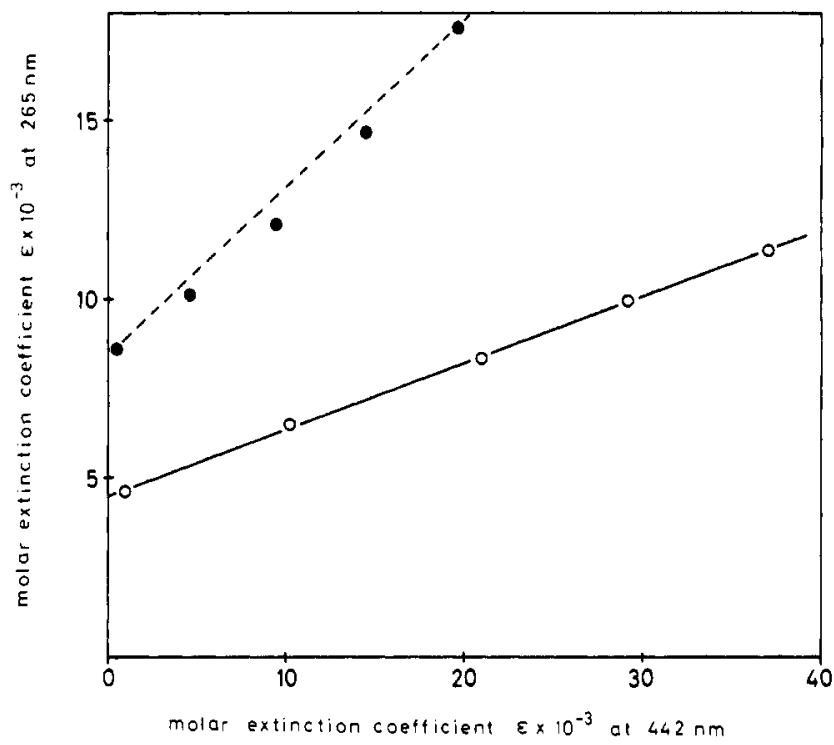

Figure 5. Change of absorbance for the merocyanine $M$ with varying $\mathrm{pH}$ at two wavelengths: correlation plot of $\epsilon_{265 \mathrm{~nm}}$ vs. $\epsilon_{442 \mathrm{~nm}}$ for the pure trans isomer solution $(O)$ and a $67: 33 \mathrm{cis} /$ trans isomer mixture $(\bullet)$. The individual pairs of absorbance values are taken from the $\mathrm{pH}$-dependent spectra in Figures $1(0)$ and $4(\bullet)$, respectively, and represent pH 6, 7, $8.5,9$, and 10 , in that order from left to right.

A thermal cis/trans isomerization of $\mathrm{MH}^{+}$in aqueous solution could not be achieved. Under rigorous exclusion of light, the cis and trans isomers are configurationally stable up to 100 ${ }^{\circ} \mathrm{C}$

Cis-Trans Isomerism of the Unprotonated Merocyanine $\mathbf{M}$. If solutions with the highest $\mathrm{MH}_{\text {cis }}^{+}$fraction obtainable pho- tochemically (67\% cis; Figure 2, spectrum C) are buffered at increasing $\mathrm{pH}$, the absorption spectra of these samples show a similar dependence on $\mathrm{pH}$ (Figure 4) as those of the pure trans form (Figure 1), with well-defined isosbestic points. The cis/trans isomer mixture apparently behaves like a single compound toward a change of $\mathrm{pH}$, i.e., both isomers must have almost the same $\mathrm{p} K$. A plot of the absorption at $442 \mathrm{~nm}$ vs. that at $265 \mathrm{~nm}$ (long and short wavelength maxima, respectively, at $\mathrm{pH} 10$ ) indeed shows only slight deviation from the straight line (Figure 5). (This would indicate that the cis form-with stronger absorbance in the $265-\mathrm{nm}$ band-has a somewhat higher $\mathrm{p} K$ than the trans form.) From this spectral behavior, it also follows that upon deprotonation of $\mathrm{MH}^{+}$both $\mathrm{M}_{\text {cis }}$ and $\mathrm{M}_{\text {trans }}$ are obtained without any change in the individual configuration. This conclusion is confirmed by the fact that the cis/trans ratio calculated from fluorescence data as described above is the same for the protonated and deprotonated form.

The hitherto unknown cis form of the merocyanine, $\mathbf{M}_{\mathrm{cis}}$, could thus be obtained by photoisomerization of $\mathrm{MH}_{\text {trans }}^{+}$and subsequent deprotonation. Contrary to $M_{\text {trans }}$, however, $M_{\text {cis }}$ is sensitive to light. On irradiating aqueous solutions containing the cis isomer with light of wavelength $\geqslant 254 \mathrm{~nm}$, the absorption spectrum changes as illustrated in Figure 6: the longwavelength band intensity increases, that of the second band decreases, and the final spectrum is identical with that of a solution prepared by dissolving crystals of $M$ in water buffered at $\mathrm{pH} \geqslant 10$ in the dark, and also with the spectrum obtained by adding alkali to a $\mathrm{MH}_{\text {trans }}^{+}$solution. The last trace of Figure 6 thus corresponds to $\mathrm{M}_{\text {trans, }}$, and the spectral change may be attributed to the photochemical cis $\rightarrow$ trans conversion of M.

Obviously, $\mathrm{M}_{\mathrm{cis}}$ is sufficiently stable in aqueous solutions

Table II. Photochemical and Photophysical Data for $\mathrm{M}$ (I) and $\mathrm{MH}^{+}$(II) at $20^{\circ} \mathrm{C}$, and Some Analogous Compounds

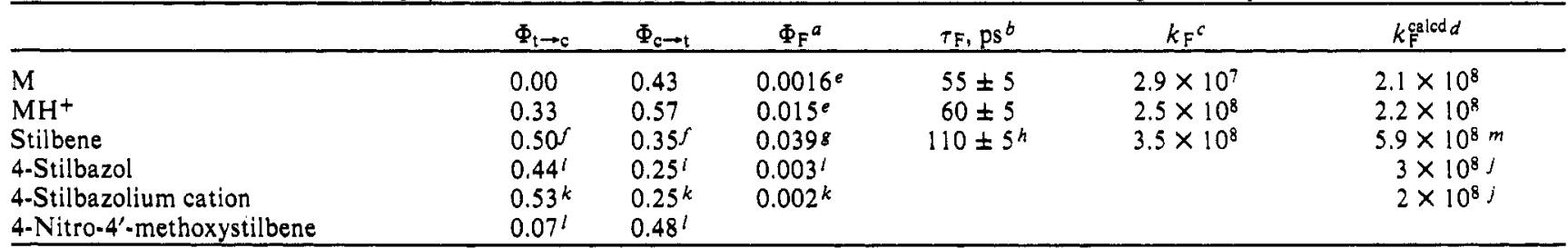

${ }^{a}$ Fluorescence quantum yield of trans isomer. ${ }^{b}$ Fluorescence lifetime as measured by phase fluorometry, ${ }^{c}$ Rate constant of fluorescence $k_{\mathrm{F}}=\Phi_{\mathrm{F}} / \tau_{\mathrm{F}}\left(\mathrm{s}^{-1}\right)$. ${ }^{d}$ Theoretical rate constants of fluorescence, calculated from the integrated absorption spectrum $\left(\mathrm{s}^{-1}\right)$. $^{e}$ Excitation wavelength at $366 \mathrm{~nm}, f$ Solvent methylcyclohexane/isopentane $(1: 3) .28 \mathrm{~g}$ Reference $39 .{ }^{h} \mathrm{C} 1 \times 10^{-3} \mathrm{~mol} / \mathrm{L}$; for isopentane and ethanol as solvents, the same $\tau_{F}$ values were obtained. 'Solvent water/ethanol (1:1), $\mathrm{pH} 8.25 j$ Reference 25 . ${ }^{k}$ Solvent water/ethanol (1:1), $\mathrm{pH} 2 .{ }^{25} / \mathrm{Solvent}$ methanol. ${ }^{27}$

$m$ Reference 40. 


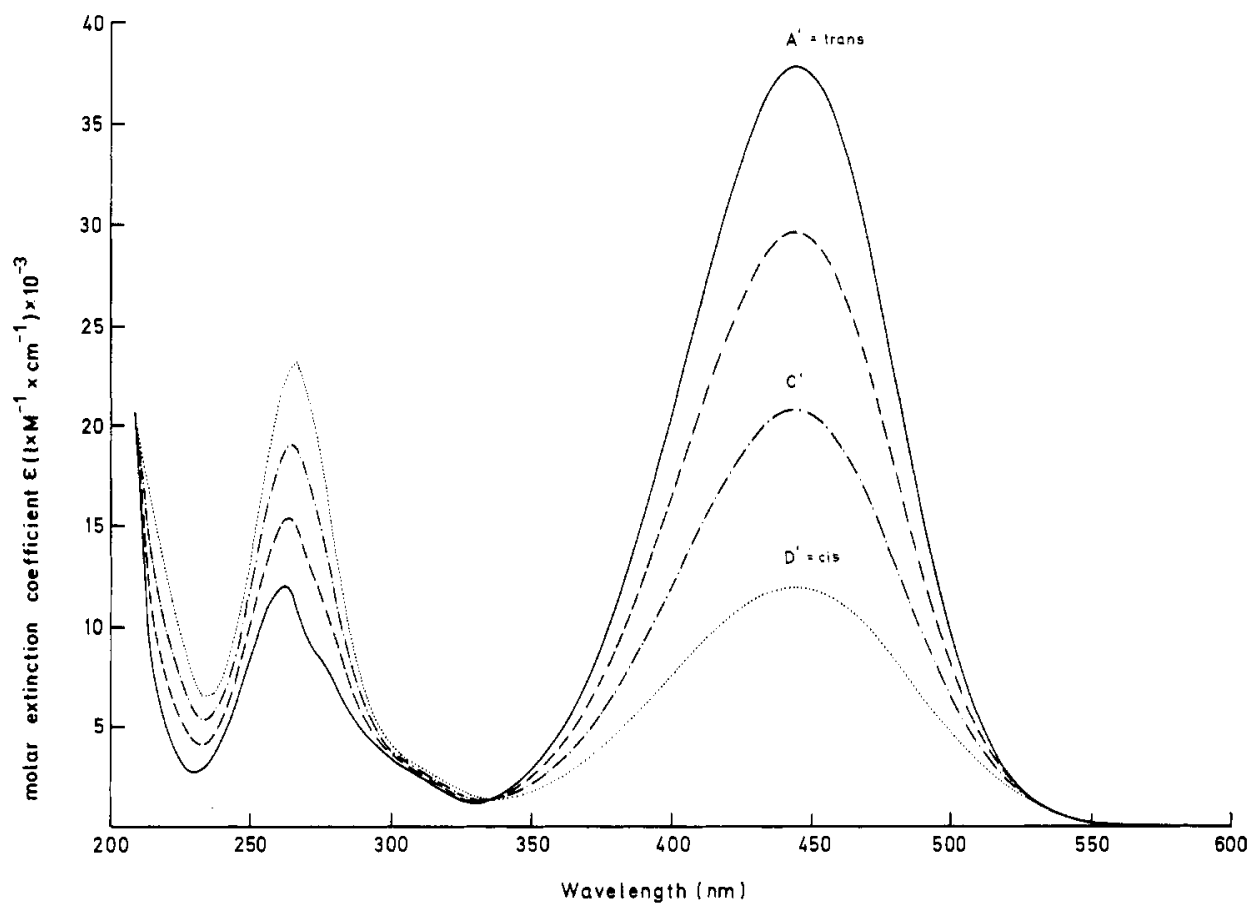

Figure 6. Spectral change for aqueous solutions of unprotonated merocyanine $\mathrm{M}$ with varying cis/trans isomer composition (total concentration $2 \times 10^{-5}$ $\mathrm{mol} / \mathrm{L}, \mathrm{pH} 10):\left(\mathrm{C}^{\prime}\right)$ spectrum of a $67: 33 \mathrm{M}_{\mathrm{cis}} / \mathrm{M}_{\text {trans }}$ isomer mixture obtained by adding $\mathrm{pH} 10$ buffer to a $\mathrm{MH}^{+}$solution with cis/trans isomer composition corresponding to the photostationary state after irradiation at $366 \mathrm{~nm}$ (see spectrum (C), Figure 2); ( A $^{\prime}$ ) spectrum of the same solution of $\mathrm{M}$ after irradiation at wavelengths $>254 \mathrm{~nm}\left(100 \% \mathrm{M}_{\text {trans }}\right)$; (D') calculated spectrum of pure cis isomer, $\mathbf{M}_{\text {cis. }}$.

to be easily identified at room temperature. Since $\mathrm{M}_{\text {trans }}$, on the other hand, is photochemically stable, $\Phi_{\mathrm{t} \rightarrow \mathrm{c}}^{\mathrm{M}}$ must be very small. Setting $\Phi_{\mathrm{t} \rightarrow \mathrm{c}}^{\mathrm{M}}=0, \Phi_{\mathrm{c} \rightarrow \mathrm{t}}^{\mathrm{M}}$ can be determined by applying eq 2 . For light of wavelength $436 \mathrm{~nm}, \Phi_{\mathrm{c} \rightarrow \mathrm{t}}^{\mathrm{M}}=0.43$ is obtained (Table II).

In contrast to $\mathrm{MH}_{\text {cis }}^{+}, \mathrm{M}_{\text {cis }}$ may also be isomerized thermally. As expected, this is a first-order reaction with strong temperature dependence (at $23^{\circ} \mathrm{C}, \tau_{1 / 2}$ is $260 \mathrm{~min}$, at $60^{\circ} \mathrm{C}$ only 1.2 $\min$ ). Rate constants $k$ were determined at temperatures between 23 and $60^{\circ} \mathrm{C}$ and evaluated in an Arrhenius plot to yield $E_{\mathrm{a}}$ and $k_{0}$. From these, enthalpy and entropy of activation were calculated according to Eyring theory. ${ }^{19}$

$$
\begin{aligned}
E_{\mathrm{a}} & =28.6 \mathrm{kcal} / \mathrm{mol} & k_{0}=7 \times 10^{16} \mathrm{~s}^{-1} \\
\Delta H_{298}^{ \pm} & =28 \mathrm{kcal} / \mathrm{mol} & \Delta S_{298}^{\ddagger}=16.5 \mathrm{eu} / \mathrm{mol}
\end{aligned}
$$

On deprotonation of $\mathrm{MH}_{\mathrm{cis}}^{+}$in methanol, no $\mathrm{M}_{\text {cis }}$ can be detected, and $\mathbf{M}_{\text {trans }}$ is obtained immediately. This means that $\mathrm{M}_{\text {cis }}$, while perfectly stable in water, is extremely transient in methanol.

\section{Discussion}

Photochemical Isomerization. The structural relationship of the merocyanine $\mathrm{M}$ and its conjugate acid $\mathrm{MH}^{+}$to stilbene, 4-stilbazole, and the 4-stilbazolium cation suggests a direct comparison of their photochemical behavior. As demonstrated by the data in Table II, the analogy holds only for $\mathrm{MH}^{+}$: the quantum yields $\Phi_{t \rightarrow c}$ and $\Phi_{c \rightarrow t}$ are of equal order of magnitude, the sum being close to unity. For the cis $\rightarrow$ trans isomerization of stilbene-type compounds, this has been explained in terms of a "phantom" state X as common intermediate in the radiationless deactivation of both the trans and the cis excited singlet state. ${ }^{20-22} \mathrm{~A} 90^{\circ}$ twisted configuration must be assumed for this phantom state because of the comparable probability for its deactivation to either trans or cis ground state. The photochemical behavior of $\mathrm{MH}^{+}$is consistent with this mechanism.

In the case of stilbene $e^{20,23,24}$ and stilbazoles, ${ }^{25,26}$ evidence has been put forward that $\mathrm{X}$ is in fact a singlet state for the direct photoisomerization. At the present state, we cannot say whether this also applies to $\mathrm{MH}^{+}$or whether any intersystem crossing is involved. In any case, the lifetime of $\mathrm{X}$ must be shorter than $5 \mathrm{~ns}$ since preliminary laser flash experiments show trans $\rightarrow$ cis conversion to be complete within $5 \mathrm{~ns}$.

In contrast to $\mathrm{MH}^{+}$and stilbene, $\Phi_{t \rightarrow c}$ is immeasurably small for the unprotonated form $\mathrm{M}$. Such a difference in the photochemical behavior of conjugate acid and base is not general as the close analogy between 4-stilbazole and 4-stilbazolium cation shows (Table II). Obviously, the change in electronic structure is more pronounced in the case of $\mathrm{O}$-protonation of the merocyanine $\mathrm{M}$ than in the case of $\mathrm{N}$-protonation of 4-stilbazole.

The photochemical properties of $\mathbf{M}$ are quite similar, though, to those of 4-nitrostilbenes substituted in the $4^{\prime}$ position with an electron-donating group, ${ }^{27,28}$ which also exhibit a very small $\Phi_{t \rightarrow c}$ in polar solvents (see data for 4-nitro-4'-methoxystilbene in Table II) and also to those of thioindigo and some of its derivatives. ${ }^{29}$

The $\Phi_{\mathrm{c} \rightarrow \mathrm{t}}$ values for $\mathrm{M}$ and $\mathrm{MH}^{+}$are not much different in accord with the general observation that quantum yields of cis $\rightarrow$ trans isomerizations are not very sensitive to substitution or solvent changes. This is generally explained with a potential curve for the excited singlet that has no minimum at or near the cis conformation-a model which also accounts for the lack of fluorescence from cis isomers.

Additional information on the mechanism of the direct photoisomerization may be obtained from fluorescence data. The fluorescence spectra of the trans isomers are in agreement with those of Kuder and Wychik. ${ }^{8}$ The respective quantum yields and lifetimes are given in Table II; neither $\mathbf{M}_{\text {cis }}$ nor $\mathrm{MH}_{\text {cis }}^{+}$shows any fluorescence according to the general rule. It is of interest, now, to compare the rate constants of fluorescence $k_{\mathrm{F}}=\Phi_{\mathrm{F}} / \tau_{\mathrm{F}}$ with theoretical values $k_{\mathrm{F}}^{\text {calcd }}$, calculated from the absorption spectrum by the Strickler-Berg equation. ${ }^{30}$ For $\mathrm{MH}^{+}$, as for stilbene, ${ }^{31}$ we find good agreement between $k_{\mathrm{F}}$ and $k_{\mathrm{F}}^{\text {calcd }}$ (Table II). This implies that the transition dipole moments of the electronic state, reached by excitation in the first absorption band, and the emitting state are 


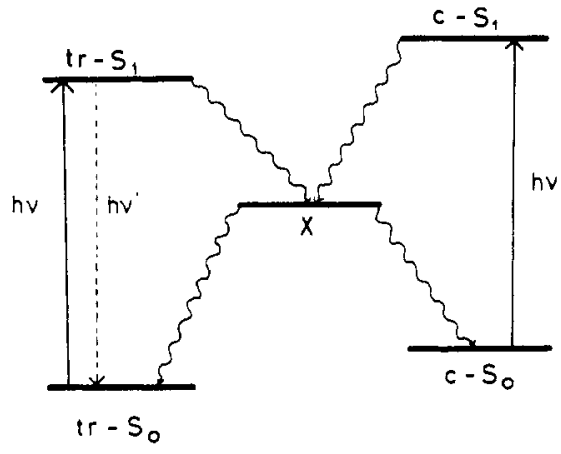

$\mathrm{MH}^{+}$

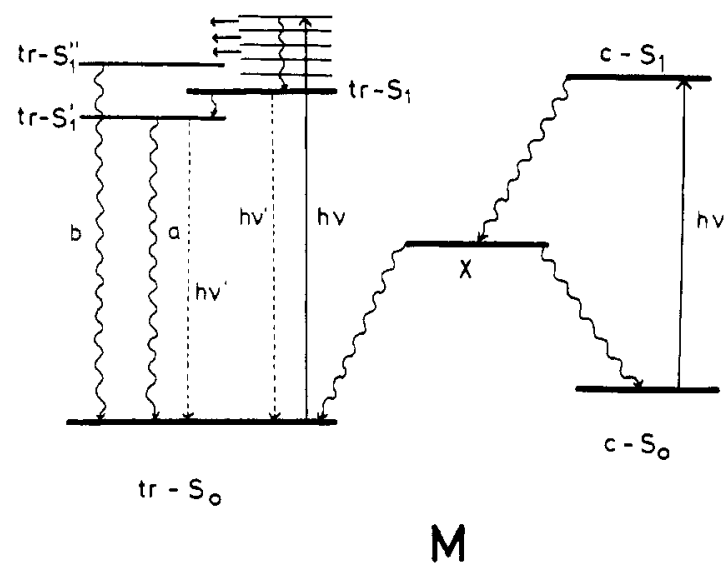

Figure 7. Possible decay mechanisms for excited cis and trans singlets of $\mathrm{MH}^{+}$and $\mathrm{M}$ (for symbol explanation, see text).

equal, and thus represents strong evidence for these two states being identical. The quantum yield for the conversion of the excited $\mathrm{MH}_{\text {trans }}^{+}$singlet to the phantom state $\mathrm{X}$ must be close to $100 \%$; consequently, this process practically determines the lifetime of the excited $\mathrm{MH}_{\text {trans }}^{+}$singlet.

For the fact that $k_{\mathrm{F}}$ is considerably smaller than $k_{\mathrm{F}}^{\text {calcd }}$ in the case of $M$, two explanations can be offered: (a) either the singlet state $S_{1}^{\prime}$, reached upon excitation, could relax very rapidly to a state $S_{1}^{\prime}$ with a smaller transition dipole moment, ${ }^{34}$ and energetically lower than $S_{1}$; (b) or thermal relaxation of the vibrationally excited $S_{1}$ state could compete with an effective internal conversion to a state $S_{1}^{\prime \prime}$ (situated somewhat above $S_{1}$ ) which is efficiently deactivated by radiationless processes.

Since $\Phi_{\mathrm{t} \rightarrow \mathrm{c}}=0$, the deactivation of either $S_{1}^{\prime}$ or $S_{1}^{\prime \prime}$ must occur without geometrical change. Therefore, these states cannot have a twisted configuration, and neither can be identical with the phantom state $X$. 7.

Our conclusions are summarized schematically in Figure

Thermal Isomerization. The close analogy between $\mathrm{MH}^{+}$ and $\mathrm{N}$-protonated stilbazoles extends also to the molecular ground state. The high thermal stability of $\mathrm{MH}_{\mathrm{cis}}^{+}$(in the dark, no isomerization is observed in aqueous solution up to $100^{\circ} \mathrm{C}$ ) clearly demonstrates that in $\mathrm{MH}^{+}$, as in stilbene, the central $\mathrm{C}-\mathrm{C}$ bond has essentially double bond character, i.e., for $\mathrm{MH}^{+}$ resonance structure IIb predominates. This conclusion is supported by quantum chemical calculations of Benson and Murrell. ${ }^{6}$ For the unprotonated merocyanine, on the other hand, the facile cis $\rightarrow$ trans isomerization is conclusive evidence of participation also of Ia; because of the large dipole moment of $\mathrm{M}$, however, Ib must still contribute significantly to the ground state, and the double bond character of the $\mathrm{C}^{5}-\mathrm{C}^{6}$ bond should still be rather pronounced. (A more quantitative in- vestigation by CNDO calculations, together with a study of the solvent dependence of the activation parameters, is in progress.)

4-Nitro-4'-methoxystilbene (III) shows close analogy to $M$ not only in its photochemical but also in its ground-state properties: the activation energy for cis $\rightarrow$ trans isomerization is $28.8 \mathrm{kcal} / \mathrm{mol}$ for $\mathrm{III}^{35}$ and $28.6 \mathrm{kcal} / \mathrm{mol}$ for M. The weight of the benzenoid structures $\mathrm{Ib}$ for $\mathrm{M}$ and IIIb for the stilbene<smiles>COc1ccc(/C=C/c2ccc(N(C)O[Na])cc2)cc1</smiles>

derivative must therefore be comparable, which also accounts for the fact that $M$ has a large ground-state dipole moment while that of III is relatively small. $4 \mathrm{~b}$

The high positive value of $+16.5 \mathrm{eu} / \mathrm{mol}$ for the entropy of activation corresponds to an extremely high frequency factor of $7 \times 10^{16} \mathrm{~s}^{-1}$. For comparison, the frequency factors for cyanines $^{36}$ and open-chain merocyanines ${ }^{37}$ are in the range of $10^{3}-10^{14} \mathrm{~s}^{-1}$, corresponding to entropies of activation of -47 to $+4.5 \mathrm{eu} / \mathrm{mol}$. It is reasonable to suppose that, in going from cis to trans in the course of the thermal isomerization process, the $90^{\circ}$ twisted configuration represents an energy maximum, i.e., the activated state of the isomerization reaction. In this configuration, the contribution of $\mathrm{lb}$ is severely attenuated, and the dipole moment is expected to be considerably smaller than in the ground state. Polar solvent molecules which initially were highly oriented due to the strong dipole moment of the planar configuration (about $30 \mathrm{D}^{4 \mathrm{~b}, 38 \text { ) }}$ thus can reorient rather freely in the activated state. This seems to be a reasonable explanation for the high positive value for the entropy of activation for this isomerization process. (This entropy change in the activated complex, by the way, corresponds to the melting of about $3 \mathrm{~mol}$ of $\mathrm{H}_{2} \mathrm{O}$.)

Molecular Reaction Cycle. The several single reactions described above constitute a full cyclic process as outlined in Scheme I. $\mathrm{MH}_{\text {trans, }}^{+}$, for instance, may be transformed photo-

Scheme I

$$
\begin{gathered}
\mathrm{MH}_{\mathrm{cis}}^{+} \stackrel{-\mathrm{H}^{+}}{\rightleftarrows} \mathrm{M}_{\mathrm{cis}} \\
h \nu\left\|_{h \nu^{\prime}} h_{\nu}\right\| \Delta\left(k_{\mathrm{th}}\right) \\
\mathrm{MH}_{\text {trans }}^{+} \stackrel{+\mathrm{H}^{+}}{\rightleftarrows} \mathrm{M}_{\text {trans }}
\end{gathered}
$$

chemically into $\mathrm{MH}_{\text {cis }}^{+}$. Deprotonation of $\mathrm{MH}_{\text {cis }}^{+}$yields $\mathrm{M}_{\text {cis, }}$, which is then isomerized to $\mathrm{M}_{\text {trans }}$ either photochemically or thermally. Subsequent protonation of $\mathbf{M}_{\text {trans }}$ completes the molecular reaction cycle. It can be traversed, however, in a "one-way" sense only since the step $\mathrm{M}_{\text {cis }} \rightarrow \mathrm{M}_{\text {trans }}$ is irreversible.

At $\mathrm{pH}$ values where both protolytic forms are present, each molecule is perpetually traversing the reaction cycle in the indicated direction. As Schulten ${ }^{41}$ pointed out to us, this oneway cycle could serve as a model ${ }^{42}$ for the role which the protonated Schiff base of retinal plays in the light-driven proton pump, discovered recently by Oesterheld and Stoeckenius in the purple membrane of Halobacterium halobium. ${ }^{43}$

Another interesting aspect of this photochemical/protolytic reaction cycle is its model character with respect to storage of information and subsequent regeneration of the information carrier. With respect to "vision" in biological systems, for instance, one might speculate on the following model process. If such a system consisted of receptors in contact with a solution containing $\mathrm{MH}_{\text {trans }}^{+}$, then the information "light" could be stored by means of the photoisomerization $\mathrm{MH}_{\text {trans }}^{+} \rightarrow \mathrm{MH}_{\mathrm{cis}}^{+}$ and then be "read" at the active sites on the receptor surface, specific for $\mathrm{MH}_{\text {cis }}^{+}$molecules. If we further assume basic properties of the receptor surface, the "information carriers" 
could be reverted to $\mathrm{MH}_{\text {trans }}^{+}$by the mechanism delineated above, thus "resetting" the system to the initial state.

Especially the potential biological model character of the merocyanine phototropism seems to us to warrant a more detailed investigation of how the individual steps of the reaction cycle depend upon both medium polarity and aryl substituents.

Acknowledgment. We gratefully acknowledge the instigation of this work by the late Professor Theodor Förster. For the NMR measurements, we thank Mr. J. Rebell; for the phase fluorometry measurements, Mr. H. P. Haar and Dr. M. Hauser. For financial assistance, we are indebted to the Fonds der Chemischen Industrie. M. H. Abdel-Kader thanks the Deutsche Akademische Austauschdienst for a stipend grant.

\section{References and Notes}

(1) (a) Institut für Physikalische Chemie; (b) Graduate Research Associate on a Ph.D. scholarship grant provided by the Deutsche Akademische Austauschdlenst, on leave from the Chemistry Department, Faculty of Science, Tanta University, Tanta, Egypt; (c) Institut für Organische Chemie, Biochemie und Isotopenforschung.

(2) L. G. S. Brooker, G. H. Keyes, and D. W. Heseltine, J. Am. Chem. Soc., 73, $5350(1951)$.

(3) S. Hünig and O. Rosenthal, Justus Liebigs Ann. Chem. 592, 161 (1955).

(4) (a) E. Lippert and F. Moll, Ber. Bunsenges. Phys. Chem., 58, 718 (1954); (b) E. Lippert, ibid., 61, 962 (1957).

(5) N. G. Bayliss and E. G. McRae, J. Am. Chem. Soc., 74, 5803 (1952).

(6) H. G. Benson and J. N. Murrell, J. Chem. Soc., Faraday Trans. 2, 137 (1972).

(7) D. Schulte-Frohlinde and H. Guesten, Justus Liebigs Ann. Chem., 749, 49 (1971).

(8) J. E. Kuder and D. Wychik, Chem. Phys. Lett., 24, 69 (1974)

(9) R. G. Bates and V. E. Bower, Anal. Chem., 28, 1322 (1956).

(10) W. H. Melhuish, J. Phys. Chem., 65, 229 (1961).

(11) M. Hauser and G. Heidt, Rev. Sci. Instrum., 46, 470 (1975).

(12) J. G. Hatchard and C. A. Parker, Proc. R. Soc. London, Ser. A, 235, 518 (1956).

(13) E. Fischer, J. Phys. Chem., 71, 3704 (1967)

(14) J. Blanc and D. L. Ross, J. Phys. Chem., 72, 2817 (1968).

(15) Though this procedure is more exact than that of Blane and Ross, ${ }^{14}$ it would be very tedious to record an entire spectrum in this manner since the concentration of one of the solutions has to be changed for every point of the spectrum

(16) H. Mauser, Z. Naturforsch. B, 23, 1025 (1968).
(17) L. M. Jackman and S. Sternhell, "Applications of Nuclear Magnetic Resonance Spectroscopy in Organic Chemistry", 2nd ed, Pergamon Press, Oxford, $1969, \mathrm{p} 302$.

(18) G. J. Martin and M. L. Martin, Prog. Nucl. Magn. Reson. Spectrosc., 8, 163 (1972).

(19) H. Eyring, Chem. Rev., 17, 65 (1935)

(20) J. Saltiel, J. Am. Chem. Soc., 89, 1036 (1967).

(21) P. Borrell and H. H. Greenwood, Proc. R. Soc. London, Ser. A, 298, 453 (1967).

(22) For a comprehensive review of stilbene photoisomerization, see J. Saltiel, J. T D'Agostino, E. D. Megarity, L. Metts, K. R. Neuberger, M. Wrighton, and O. C. Zafiriou, Org. Photochem., 3, 1 (1973).

(23) J. Saltiel and E. D. Megarity, J. Am. Chem. Soc., 94, 2742 (1972).

(24) G. Orlandi and W. Siebrand, Chem. Phys. Lett., 30, 352 (1975).

(25) G. Bartocci, P. Bortolus, and U. Mazzucato, J. Phys. Chem., 77, 605 (1973).

(26) D. G. Whitten and Y. J. Lee, J. Am. Chem. Soc., 94, 9142 (1972).

(27) D. Schulte-Frohlinde, H. Blume, and H. Guesten, J. Phys. Chem., 66, 2486 (1962).

(28) D. Gegiou, K. A. Muszkat, and E. Fischer, J. Am. Chem. Soc., 90, 3907 (1968).

(29) A. D. Kirsch and G. M. Wyman, J. Phys. Chem., 81, $413(1977)$.

(30) S. J. Strickler and R. A. Berg, J. Chem. Phys., 37, 814 (1962).

(31) Our value of $110 \mathrm{ps}$ for the fluorescence of stilbene is much shorter than the $1.5 \mathrm{~ns}$ reported by Birch and Birks. ${ }^{32}$ These authors used a single photon counting technique which could not resolve processes shorter than 200 ps. They mention a fast component in the fluorescence decay of stilbene which they could not resolve and which is probably what we have measured. Heumann et al. ${ }^{33}$ on the other hand, observe the fast formation of a decay product of $S_{1}$ trans-stilbene, with a rate of formation consistent with our $S_{1}$ lifetime.

(32) D. J. S. Birch and J. B. Birks, Chem. Phys. Lett., 38, 432 (1976).

(33) E. Heumann, W. Triebel, R. Uhlmann, and B. Wilhelmi, Chem. Phys. Lett., $45,425(1977)$.

(34) As there is a strong decrease of the dipole moment of $M$ upon excitation, 46,38 excitation will result in solvent reorientation. We do not believe, though, that this solvent relaxation is responsible for the large increase in radiative lifetime. Since the first excited singlet state of $M$ has a smaller dipole moment than the ground state, it is reasonable to assume that the reorientation of the polar solvent has a similar effect on the transition as if a less polar solvent was used. Benson and Murrell ${ }^{6}$ have both measured and calculated the oscillator strength of $M_{\text {trans }}$ for solvents of varying polarity, and find a variation of oscillator strength by a factor of only 2 .

(35) M. Calvin and H. W. Alter, J. Chem. Phys., 19, 768 (1951).

(36) F. Dörr, J. Kotschy, and H. Kausen, Ber. Bunsenges. Phys. Chem., 69, 11 (1965).

(37) E. Joerges, S. Schneider, and F. Dörr, Ber. Bunsenges. Phys. Chem., 80, 639 (1976).

(38) G. Rasch, Z. Chem., 2, 5 (1962).

(39) S. Sharafi and K. A. Muszkat, J. Am. Chem. Soc., 93, 4119 (1971)

(40) A. Marinarl and J. Saltiel, Mol, Photochem., 7, 225 (1976).

(41) K. Schulten, personal communication.

(42) K. Schulten and P. Tavan, Nature (London), in press.

(43) D. Oesterheld and W. Stoeckenius, Proc. Natl. Acad. Sci. U.S.A., 70, 2853 (1973). 